\title{
Theory Research of Value Investing Based on Market Position
}

\author{
Lixia Wang ${ }^{1} \&$ Lining Gan $^{2}$ \\ ${ }^{1,2}$ SHU-UTS SILC Business School, Shanghai University, China. \\ Correspondence: Lixia Wang, SHU-UTS SILC Business School, Shanghai University, No.20 ChengZhong Road, \\ Jiading District, Shanghai, China. Tel: 86-21-6998-0028.
}

Received: January 27, 2016

Accepted: February 14, 2016

Available online: February 23, 2016

doi:10.11114/aef.v3i2.1401

URL: http://dx.doi.org/10.11114/aef.v3i2.1401

\begin{abstract}
:
This paper divides the net assets of a company into net operating assets (Equity) and net financial assets on the basis of Ohlson residual income model. Under the assumption that excess surplus income can only be generated from the net operating assets, the account of unearned revenue is selected as an efficient indicator reflecting a company's market position and a new model of value investing theory is built based on market position. Moreover, statistics of Chinese capital market from 2003 to 2011 are used to conduct an empirical analysis to test the adjusted theoretical model. The results show that unearned revenue would significantly affect corporations' equity value as an indicator reflecting its market position. However, an extreme value appears in its influence curve which performs as an inverted U shape. Overall, adjusted model of value investing theory built in this paper has important theoretical and practical significance in improving the development of China's capital market.
\end{abstract}

Keywords: Value investing, Market position, Unearned revenue

\section{Introduction}

Chinese capital market starts later, which is only a short period time of more than twenty years, so, it is still in the stage of "emerging and transition" and described as the capital market of policy-driven. However, due to the boom of Chinese economy, China's capital market develops rapidly and has turned into the world's second largest capital market. Meanwhile, Chinese investors have also grown more mature with a further acceptance of the value investing theory and a wider usage for actual investment decision-making.

Some theories of value investing are more mature in developed western countries. A number of models of these theories have been developed, such as Discount Free Cash Flow Model(DCF), Dividend Discount Mode(DDM), Residual Income Valuation Model(RIM). Focusing on these value investing models, Chinese researchers have carried out considerable theoretical and empirical studies. All researches have proved that these models have certain applicability in China's capital market to varying degrees.

However, the development of Chinese economy has its own particularity without a completely free competitive market. In China's capital market, corporations with larger scale and higher market position can acquire much more competitive advantages comparing with small \&medium-sized companies, which could results more excess profits. Generally, a higher market status means a stronger position when negotiating and a larger capability to require enterprises to pay in advance. Conversely, a lower market position often leads to the difficulty in collecting unearned revenue, and even receivables with long-term collection period after delivered their goods.

Based on Ohlson's model and the consideration of market position, this paper tries to build a new model of the value investing theory for further study on the relationship between market position and corporations' equity value by studying the account "unearned revenue receivable" as its role in indicating market position of corporations, focusing on the listed companies of the manufacturing industry and using statistics from Chinese capital market.

\section{Literature Review}

Fisman and Raturi(2004) and Van Horen(2005) proposed the hypothesis of the competitiveness of commerce credit and got the result that the companies with higher market position have stronger ability to get commercial credit. Jinlin $\mathrm{Lu}$ (2013) made an empirical study using the data come from china's capital from the year 2008 to 2011 and got a result that companies have better profitability when they have stronger market position. 
Lixia Wang,Lining Gan (2015) construct residual income model based on market position adjustment, whose conclusion proves its validity and applicability,but in the empirical year, not all year is remarkable.This paper argues that one of the important reasons may be the failure to consider the properties of the assets.The company's net assets can be divided into operating net assets and financial net assets,at the same time,the operating net assets will generate abnormal residual income,and financial net assets will not produce abnormal residual income, which can only get the average return on capital risk under effective capital market.Based on this,this paper carries on the research on it for the pertinence and the improvement.

\section{Research Hypotheis And Model Construction}

\subsection{Research Hypothesis and Proposition}

3.1.1 Assumption : A company's net assets (Equity) can be divided into net operating assets and net financial assets, and abnormal residual income can only be generated from the net operating assets. Net financial assets can only obtain the average risk returns on capital in an efficient capital market. Namely: $\mathrm{BV}=\mathrm{FA}+\mathrm{OA}$

In the equation:

BV means a company's net assets;

FA means a company's net financial assets;

OA means a company's net operating assets.

The assumption is reasonable because the capital market is views as a fully competitive and maturity under market economy. According to the Fisher Effect, net financial assets can only acquire the average risk returns on capital that is $R_{f}$.

\subsubsection{Proposition}

Proposition I: There is a positive relationship between the intrinsic value of a corporation's equity and its unearned revenue. The relationship is shown as follows:

$$
\mathrm{Val}_{t}=O \mathrm{~A}_{t}+F \mathrm{~A}_{t}+\alpha X_{t}+\beta Y_{t}+\gamma U_{t}+\varepsilon_{t}
$$

In the equation:

$\mathrm{Val}_{t}$ means a company's equity value per share in the t period;

$O A_{t}$ means a company's net operating assets per share in the t period;

$F A_{t}$ means a company's net financial assets per share in the t period;

$X_{t}$ means a company's abnormal residual income per share in the t period;

$Y_{t}$ means a company's accounts receivable per share at the end of the t period;

$U_{t}$ means other factors that would affect a company's equity value per share in the t period;

$\varepsilon_{t}$ means the zero-mean random factors that would affect a company's equity value per sharer in the t period.

Known constants $\alpha 、 \beta 、 \gamma$ respectively means the parameter of each coefficient .

Proposition II: Although there is a positive correlation between the intrinsic value of the enterprise equity and unearned revenue,but it is negative correlation with quadratic form. That is, the correlation line between the two variables is inverted $\mathrm{U}$-distribution that has a maximum value.

$$
V a l_{t}=F A_{t}+O A_{t}+\alpha X_{t}+\beta_{1} Y_{t}+\beta_{2} Y_{t}^{2}+\gamma U_{t}+\varepsilon_{t}
$$

In the equation:

Known constants $\beta_{1} 、 \beta_{2}$ relatively means the parameter of coefficient $Y_{t} 、 Y_{t}^{2}$.

The significance of the other letters is the same as above.

\subsection{Model Reasoning and Theoretical Basis}

Based on the assumption mentioned above, a company's abnormal residual income can be shown as follows:

$$
X_{t}=N I_{t}-O A_{t} * r-F A_{t} * R_{f}
$$

The significance of the other letters is the same as above.

In the equation: 
$N I_{t}$ means a company's net profits per share in the t period;

$r$ means risk-free rate of return on capital;

$R_{f}$ means risk rate of return

The relationship between $r$ and $R_{f}$ is $R_{f}=1+\mathrm{r}$

Using Feltham and Ohlson (1995) residual income model to compute intrinsic value of a corporation's equity.

$$
\begin{aligned}
& V a l_{t}=B V_{t}+\sum_{\tau=1}^{\infty} R_{f}^{-\tau} E_{t}\left[X_{t+\tau}\right] \\
& X_{t+1}=\omega X_{t}+v_{t}+\varepsilon_{1 t+1} \\
& v_{t+1}=\varphi v_{t}+\varepsilon_{2 t+1}
\end{aligned}
$$

In the equation:

$E\left[X_{t+\tau}\right]$ means the expectation of abnormal residual income in the $t+\tau$ period;

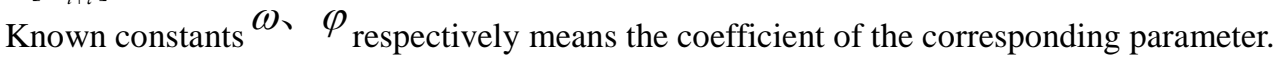

The significance of the other letters is the same as above.

Thus, based on the equation (4), proposition I and proposition II can be made the following transforms independently:

For proposition I:

For proposition II:

$$
\begin{aligned}
& V a l_{t}=F A_{t}+O A_{t}+\sum^{\infty} R_{f}^{-\tau} E_{t}\left[X_{t+\tau}\right] \\
& X_{t+1}=\omega X_{t}+\xi Y_{t}^{+1} \quad{ }_{t}^{+} \varepsilon_{1+} \\
& Y_{t+1}=m Y_{t}+\varepsilon_{2+t} \\
& v_{t+1}=\varphi v_{t}+\varepsilon_{3+t}
\end{aligned}
$$

In the equations:

$$
\begin{aligned}
& V a l_{t}=F A_{t}+O A_{t}+\sum^{\infty} R_{f}^{-\tau} E_{t}\left[X_{t+\tau}\right] \\
& X_{t+1}=\omega X_{t}+\xi_{1} Y_{t}+\xi_{2} Y_{t}^{\mathfrak{D}}+v_{t}+\varepsilon_{1 t+1} \\
& Y_{t+1}=m Y_{t}+\varepsilon_{2 t+1} \\
& v_{t+1}=\varphi v_{t}+\varepsilon_{3 t+1}
\end{aligned}
$$

Constants $\xi 、 \xi_{1}, \xi_{2}$ each represents the coefficient of the corresponding parameter.

The significance of the other letters is the same as above.

$\omega 、 m$ and $\varphi$ can be each represented abnormal surplus、 market position and other information's sustainability. The values of these three variables range from 0 to 1 .

Plugging equation (5) and (6) into equation (4) respectively, the following two transforms can be obtained as equation (7) and equation (8) after mathematical arrangement.

$$
\begin{aligned}
& \mathrm{Val}_{t}=F A_{t}+O A_{t}+\alpha X+\beta Y+{ }_{t} \gamma U \\
& \alpha=\frac{1}{R_{f}-\omega} \\
& \left.\beta=\frac{R_{f} \xi}{\left(R_{f}-\omega\right) R_{f}-m}\right) \\
& \gamma=\frac{R_{f} \varphi}{\left.\left(R_{f}-\omega\right) R_{f}-\varphi\right)}
\end{aligned}
$$




$$
\begin{aligned}
& \mathrm{Val}_{t}=F A_{t}+O A_{t}+\alpha X_{t}+\beta_{1} Y_{t}+\beta_{2} Y_{t}^{2}+\gamma U_{t} \\
& \alpha=\frac{1}{R_{f}-\omega} \\
& \beta_{1}=\frac{R_{f} \xi_{1}}{\left(R_{f}-\omega\right)\left(R_{f}-m\right)} \\
& \beta_{2}=\frac{R_{f} \xi_{2}}{\left(R_{f}-\omega\right)\left(R_{f}-m^{2}\right)} \\
& \gamma=\frac{R_{f} \varphi}{\left(R_{f}-\omega\right)\left(R_{f}-\varphi\right)}
\end{aligned}
$$

Theoretically, the proposition I (equation 1) and the proposition II (equation 2) are confirmed by equation (7) and (8) respectively. That is , the two propositions are both theoretically feasible ,raising on the base of Feltham and Ohlson (1995) residual income model .

\subsection{Setting of empirical model}

For other factors of formula (7) and (8),namely variable , this paper use the treatment of the empirical research proposed by Myers (1999), which adds an intercept to ignore the "other information",and this is an equivalent transformation in Mathematics.From this, the above formula (7) and (8) can be converted into the following empirical model:

$$
\begin{aligned}
& \mathrm{Val}_{t}=\alpha_{0}+F A_{t}+O A_{t}+\alpha X{ }_{t} \beta Y \\
& \alpha=\frac{1}{R_{f}-\omega} \\
& \beta=\frac{R_{f} \xi}{\left.\left(R_{f}-\omega\right) R_{f}-m\right)} \\
& V a l_{t}=\alpha_{0}+F A_{t}+O A+\alpha X+{ }_{t} \beta Y+_{t} \beta Y_{2}^{2} \\
& \alpha=\frac{1}{R_{f}-\omega} \\
& \beta_{1}=\frac{R_{f} \xi_{1}}{\left.\left(R_{f}-\omega\right) R_{f}-m\right)} \\
& \left.\beta_{2}=\frac{R_{f} \xi_{2}}{\left(R_{f}-\omega\right) R_{f}-m^{2}}\right)
\end{aligned}
$$

In the equation:

$\alpha_{0}$ means the intercept coefficient.

The significance of the other letters is the same as above.

\section{Empirical Test}

4.1 The estimated value span of each correlation coefficient based on the practical significance of accounting.

\begin{tabular}{l|l}
\hline Coefficient & Range of values \\
\hline $\boldsymbol{\omega}$ & {$[0,1]$} \\
\hline$m$ & {$[0,1]$} \\
\hline$\varphi$ & {$[0,1]$} \\
\hline$\alpha$ & {$[0,+\infty)$} \\
\hline$\beta$ & {$[0,+\infty)$} \\
\hline$\beta_{1}$ & {$[0,+\infty)$} \\
\hline$\beta_{2}$ & $(-\infty, 0]$ \\
\hline
\end{tabular}

By using the equation (7) and (8), the theoretical value of the actual accounting data getting from the listed companies can be computed. In view of Efficient Market Hypothesis (EMH), a stock price is set depending on its intrinsic value in 
the efficient market. Meanwhile, the price per share is also valued intrinsically in all empirical studies on the judgment of equity value. Moreover, plenty of empirical researches have shown that a linear relationship exists between the stock quote and its value, which is $P_{t}=c_{0}+c_{1}$ Val $_{t}+\varepsilon_{t}\left(c_{0}\right.$. $c_{1}$ are both known coefficients). Thus, the value of variable $\operatorname{Val}$ in the equations mentioned above can be substituted by the corresponding share price $\mathrm{p}$ in the following empirical test.

\subsection{Definition of Variables and Data Description}

All the statistics appear in this empirical study are the actual annual data collected from corresponding annual reports on WIND database. Each variable's description and accounting practice are shown as follows:

$P$ : The price per share (without dividend offering).

FA: The book value per share of net financial assets on the date of balance sheet.

OA: The book value per share of net operating assets on the date of balance sheet.

NI: Net profits per share (net profits in the t period/ the total common shares at the end of the t period).

$R_{f}$ : Free-risk rate of return $\mathrm{r}$ plus 1 , and $\mathrm{r}$ is accounted as one-year bond interest rate.

$X$ : Abnormal surplus per share (excess surplus per share in the t period=[net profits in the t period-r*the net operating assets in the period(t-1)- $R_{f} *$ the net financial assets in the period(t-1)]/total common shares at the end of the t period).

This paper selected all the listed companies in the manufacturing industry in Shanghai and Shenzhen markets from 2003 to 2011 as empirical study objects, and both the accounting data and stock price are obtained from WIND Database. Additionally, closing price per share on April 30th in each year is viewed as the stock price for last year in this paper because the fact that every listed corporation is required to disclose its last year's annual report before April 30th this year. In addition, if the stock market is closed on April 30th for a holiday or other reasons, the closing price of the previous trading day should be used for computation.

\subsection{Samples Selection And Variables Description}

\subsubsection{Samples Selection, see table 1 below.}

Table 1. Samples size selection

\begin{tabular}{|c|c|c|c|c|c|}
\hline year & 2003 & 2004 & 2005 & 2006 & 2007 \\
\hline Manufacturing enterprises & 752 & 820 & 821 & 873 & 943 \\
\hline \multirow{2}{*}{ Reduction: STPT } & -45 & -51 & -46 & -57 & -76 \\
\hline & 707 & 769 & 775 & 816 & 867 \\
\hline \multirow{2}{*}{ Reduction:price absence } & -41 & -54 & -68 & -77 & -45 \\
\hline & 656 & 715 & 707 & 739 & 822 \\
\hline \multirow{2}{*}{ Reduction:carrying value absence } & -47 & -73 & -15 & -63 & -87 \\
\hline & 609 & 642 & 692 & 676 & 735 \\
\hline Reduction: the ultimate control absence & 0 & 0 & 0 & 0 & 0 \\
\hline sample & 609 & 642 & 692 & 676 & 735 \\
\hline
\end{tabular}


Table 1. sample selection procedures (continued)

\begin{tabular}{llllll}
\hline year & 2008 & 2009 & 2010 & 2011 & Total \\
\hline Manufacturing enterprises & 977 & 1030 & 1188 & 1275 & 8679 \\
Reduction: STPT & -56 & -41 & -61 & -55 & -508 \\
& 921 & 989 & 1127 & 1220 & 8191 \\
Reduction:price absence & -51 & -75 & -48 & -60 & -529 \\
& 870 & 914 & 1079 & 1160 & 7662 \\
Reduction:carrying value absence & -50 & -79 & -87 & -114 & -715 \\
Reduction: the ultimate control absence & 0 & 835 & 892 & 1046 & 6947 \\
Final samples size & 820 & -2 & -2 & -3 & -7 \\
\hline
\end{tabular}

4.3.2 Descriptive statistical analysis of variables, see table 2 below.

Table 2. Descriptive statistics of variables

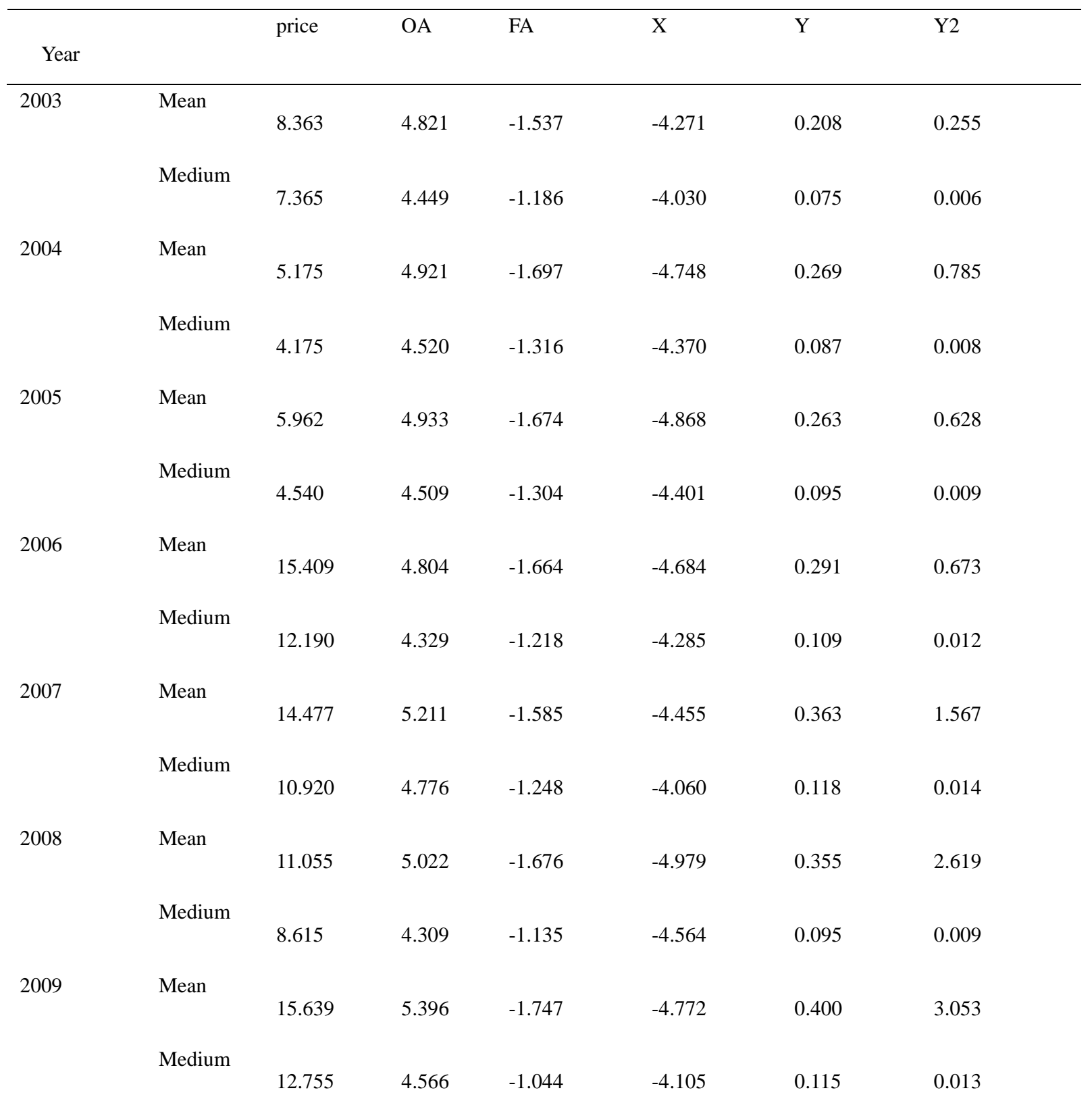




\begin{tabular}{|c|c|c|c|c|c|c|c|}
\hline 2010 & Mean & 17.609 & 5.876 & -1.765 & -5.254 & 0.397 & 1.527 \\
\hline \multirow{4}{*}{2011} & \multirow[t]{2}{*}{ Medium } & & & & & & \\
\hline & & 14.160 & 5.052 & -0.940 & -4.400 & 0.112 & 0.013 \\
\hline & \multirow[t]{2}{*}{ Mean } & & & & & & \\
\hline & & 12.810 & 6.453 & -1.801 & -6.095 & 0.360 & 1.172 \\
\hline \multirow{4}{*}{$\begin{array}{l}\text { Total } \\
\text { samples }\end{array}$} & \multirow[t]{2}{*}{ Medium } & & & & & & \\
\hline & & 10.100 & 5.582 & -0.976 & -5.234 & 0.112 & 0.013 \\
\hline & Mean & 12.217 & 5.355 & -1.694 & -4.978 & 0.331 & 1.439 \\
\hline & Medium & 9.550 & 4.686 & -1.142 & -4.369 & 0.102 & 0.010 \\
\hline
\end{tabular}

From table 2 , it can be found that both the mean and median of the stock price decreased from 2003 to 2005, and then abruptly rose in 2006 before started falling in the following two years until increased again from 2009 and ended with a fall in 2011. However, this fluctuation phenomenon did not exist in the changes of mean and median of either operating or financial equity value which appear remaining stable in the long run. Meanwhile, the value of unearned revenue per share fluctuated little. Its highest mean value arisen in 2009, which can be contributed to the 2008 financial crisis that caused many corporations to collect more unearned revenue in order to avoid financial risks.

\subsection{Results Of Empirical Test}

4.4.1 Results of empirical test of proposition I,see table 3 below.

Table 3. Results of empirical test of proposition I

\begin{tabular}{|c|c|c|c|c|c|}
\hline Year & 2003 & 2004 & 2005 & 2006 & 2007 \\
\hline Intercept & $\begin{array}{l}4.87713 \\
(<.0001) * * *\end{array}$ & $\begin{array}{l}1.95979 \\
(<.0001) * * *\end{array}$ & $\begin{array}{l}1.74271 \\
(0.0002) * * *\end{array}$ & $\begin{array}{l}7.83604 \\
(<.0001) * * *\end{array}$ & $\begin{array}{l}5.65519 \\
(<.0001) * * *\end{array}$ \\
\hline OA & $\begin{array}{l}1.58236 \\
(<.0001) * * *\end{array}$ & $\begin{array}{l}1.24932 \\
(<.0001) * * *\end{array}$ & $\begin{array}{l}1.8336 \\
(<.0001) * * *\end{array}$ & $\begin{array}{l}3.95157 \\
(<.0001) * * *\end{array}$ & $\begin{array}{l}4.03478 \\
(<.0001) * * *\end{array}$ \\
\hline FA & $\begin{array}{l}1.25379 \\
(<.0001) * * *\end{array}$ & $\begin{array}{l}1.46293 \\
(<.0001) * * *\end{array}$ & $\begin{array}{l}2.06423 \\
(<.0001) * * *\end{array}$ & $\begin{array}{l}3.41392 \\
(<.0001) * * *\end{array}$ & $\begin{array}{l}1.98664 \\
(<.0001) * * *\end{array}$ \\
\hline$X$ & $\begin{array}{l}0.57067 \\
(<.0001) * * *\end{array}$ & $\begin{array}{l}0.12829 \\
(0.188)\end{array}$ & $\begin{array}{l}0.34035 \\
(0.0137) * *\end{array}$ & $\begin{array}{l}1.36956 \\
(<.0001) * * *\end{array}$ & $\begin{array}{l}2.12363 \\
(<.0001) * * *\end{array}$ \\
\hline Y & $\begin{array}{l}0.98345 \\
(0.0003) * * *\end{array}$ & $\begin{array}{l}0.59498 \\
(<.0001) * * *\end{array}$ & $\begin{array}{l}1.08459 \\
(<.0001) * * *\end{array}$ & $\begin{array}{l}2.35949 \\
(<.0001) * * *\end{array}$ & $\begin{array}{l}1.11666 \\
(0.0008) * * *\end{array}$ \\
\hline $\begin{array}{l}\text { Observed } \\
\text { value }\end{array}$ & 609 & 642 & 6992 & 676 & 7335 \\
\hline $\mathrm{F}$ & 74.04 & 53.44 & 53.32 & 70.39 & 84.98 \\
\hline Adjusted & 0.3246 & 0.2466 & 0.2325 & 0.2914 & 0.3140 \\
\hline
\end{tabular}

$\mathrm{P}$-value statistics in parenthesis; *** means that the variable is significant at $1 \%$ level; ** means the that the variable is significant at $5 \%$ level; * means that the variable is significant at $10 \%$ level.

Table 3. Results of empirical test of proposition I (Continued)

\begin{tabular}{llllll}
\hline Year & 2008 & 2009 & 2010 & 2011 & Total samples \\
\hline Intercept & 4.64404 & 8.02624 & 6.60548 & 3.77843 & 4.61394 \\
& $(<.0001) * * *$ & $(<.0001) * * *$ & $(<.0001) * * *$ & $(<.0001) * * *$ & $(<.0001) * * *$ \\
OA & 2.86544 & 3.27267 & 3.88551 & 2.56552 & 3.14614
\end{tabular}




\begin{tabular}{llllll}
\hline & $(<.0001) * * *$ & $(<.0001) * * *$ & $(<.0001) * * *$ & $(<.0001) * * *$ & $(<.0001) * * *$ \\
FA & 2.85329 & 3.23364 & 3.71452 & 2.92478 & 2.85264 \\
& $(<.0001) * * *$ & $(<.0001) * * *$ & $(<.0001) * * *$ & $(<.0001) * * *$ & $(<.0001) * * *$ \\
$\mathrm{X}$ & 0.70686 & 0.95817 & 1.06022 & 0.46888 & 0.95551 \\
& $(<.0001) * * *$ & $(<.0001) * * *$ & $(<.0001) * * *$ & $(<.0001) * * *$ & $(<.0001) * * *$ \\
$\mathrm{Y}$ & 0.87668 & 0.3988 & 0.77137 & 1.6758 & 1.00452 \\
& $(<.0001) * * *$ & $(0.0241) * *$ & $(0.0239) * *$ & $(<.0001) * * *$ & $(<.0001) * * *$ \\
Observed & 820 & 833 & 890 & 1043 & 6940 \\
value & & & & & 131.45 \\
F & 139.32 & 115.31 & 115.29 & 0.3337 & 724.86 \\
Adjusted & 0.4032 & 0.3546 & 0.3396 & & 0.2944 \\
R2 & & & &
\end{tabular}

P-value statistics in parenthesis; $* * *$ means that the variable is significant at $1 \%$ level; ** means the that the variable is significant at 5\% level; * means that the variable is significant at $10 \%$ level.

Table 3 shows that the effect of unearned revenue indicating market position on corporate equity is statistically significant each year in the period of 2003 to 2011. Furthermore, the effect is significant at $1 \%$ level in seven years and at $5 \%$ level in 2009 and 2010. Based on empirical analysis on table 3, the consequence that unearned revenue reflecting a company's market position positively effect corporate equity can be drawn. Thus, the proposition I is verified and the model proposed in equation (9) conforms to Chinese capital market.

4.4.2 Results of empirical test of proposition II, see table 4 below.

Table 4. results of empirical test of proposition II

\begin{tabular}{llllll}
\hline Year & 2003 & 2004 & 2005 & 2006 & 2007 \\
\hline Intercept & 4.91524 & 1.98308 & 1.7124 & 7.75852 & 5.61002 \\
& $(<.0001) * * *$ & $(<.0001) * * *$ & $(0.0003) * * *$ & $(<.0001) * * *$ & $(<.0001) * * *$ \\
OA & 1.58863 & 1.19557 & 1.77821 & 3.9139 & 3.97741 \\
& $(<.0001) * * *$ & $(<.0001) * * *$ & $(<.0001) * * *$ & $(<.0001) * * *$ & $(<.0001) * * *$ \\
FA & 1.25256 & 1.4222 & 2.03016 & 3.39913 & 1.96255 \\
& $(<.0001) * * *$ & $(<.0001) * * *$ & $(<.0001) * * *$ & $(<.0001) * * *$ & $(<.0001) * * *$ \\
X & 0.57321 & 0.12595 & 0.33679 & 1.41394 & 2.11098 \\
& $(<.0001) * * *$ & $(0.1938)$ & $(0.0143) * *$ & $(<.0001) * * *$ & $(<.0001) * * *$ \\
Y & 0.55003 & 1.38758 & 2.31875 & 4.52132 & 1.99591 \\
& $(0.2869)$ & $(<.0001) * * *$ & $(<.0001) * * *$ & $(<.0001) * * *$ & $(0.0052) * * *$ \\
Y2 & 0.12075 & -0.06673 & -0.1528 & -0.27805 & -0.04466 \\
Observed & $(0.323)$ & $(0.0055) * * *$ & $(0.0101) * *$ & $(0.0085) * * *$ & $(0.1636)$ \\
value & 609 & 642 & 692 & 676 & 735 \\
F & 59.42 & 44.75 & 44.34 & 58.21 & 68.46 \\
Adjusted & 0.3245 & 0.2545 & 0.2387 & 0.2976 & 0.3148 \\
R2 & & & & &
\end{tabular}

P-value statistics in parenthesis; *** means that the variable is significant at $1 \%$ level; ** means the that the variable is significant at 5\% level; * means that the variable is significant at $10 \%$ level.

Table 4. Results of empirical test of proposition II (continued)

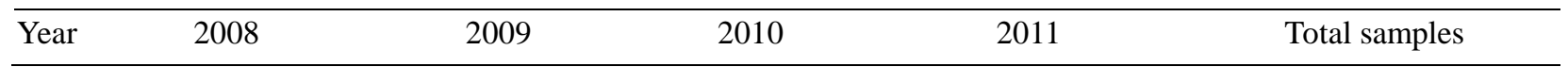




\begin{tabular}{llllll}
\hline Intercept & 4.63935 & 8.005 & 6.48329 & 3.55712 & 4.57282 \\
& $(<.0001) * * *$ & $(<.0001) * * *$ & $(<.0001) * * *$ & $(<.0001) * * *$ & $(<.0001) * * *$ \\
OA & 2.83433 & 3.25078 & 3.79934 & 2.46392 & 3.0922 \\
& $(<.0001) * * *$ & $(<.0001) * * *$ & $(<.0001) * * *$ & $(<.0001) * * *$ & $(<.0001) * * *$ \\
FA & 2.83427 & 3.20835 & 3.69691 & 2.90609 & 2.82159 \\
& $(<.0001)^{* * *}$ & $(<.0001) * * *$ & $(<.0001) * * *$ & $(<.0001) * * *$ & $(<.0001) * * *$ \\
X & 0.69973 & 0.97076 & 1.01869 & 0.43158 & 0.94457 \\
& $(<.0001)^{* * *}$ & $(<.0001) * * *$ & $(<.0001) * * *$ & $(0.0002) * * *$ & $(<.0001) * * *$ \\
Y & 1.21772 & 0.89175 & 2.06294 & 3.98765 & 1.82768 \\
& $(0.0006) * * *$ & $(0.0398) * *$ & $(0.0018) * * *$ & $(<.0001) * * *$ & $(<.0001) * * *$ \\
Y2 & -0.01063 & -0.01361 & -0.08609 & -0.18443 & -0.03454 \\
Observed & $(0.2957)$ & $(0.2131)$ & $(0.0226) * *$ & $(<.0001) * * *$ & $(<.0001) * * *$ \\
value & 820 & 833 & 890 & 1043 & 6940 \\
F & $111.69 * * *$ & $92.62 * * *$ & $93.71 * * *$ & $112.52 * * *$ & $589.32 * * *$ \\
Adjusted & 0.4033 & 0.3551 & 0.3427 & 0.3486 & 0.2977 \\
R2 & & & & &
\end{tabular}

P-value statistics in parenthesis; $* * *$ means that the variable is significant at $1 \%$ level; ** means the that the variable is significant at $5 \%$ level; * means that the variable is significant at $10 \%$ level.

From table 4 it can be found that about 9 years,from 2003 to 2010, the quadratic of unearned revenue is negatively related to equity value for 8 years except for 2003 and totally it is statistically significant for 6 years.

It is can be concluded that unearned revenue reflecting an enterprise's market statue have positive influence on the company's equity value while there is a negative relationship between quadratic unearned revenue and corporate equity. So, the relationship between these two variables is inverted U-shape which has the extreme value. The empirical results confirm the proposition II and the applicability of the model developed in equation (10) in Chinese capital market.

\subsection{Robust Test}

In order to further test the robustness of empirical results, free-risk rate of return is replaced for the following experiments. Both table 3 and table 4 above-mentioned use the one-year bond rate and it is substituted by annual bank loan rate in model 1 showing in table 5 and table 6. Besides, in model 2, fully diluted earnings per share replaces earnings per share in table 3 and table 4 to reckon abnormal return. All results are presented in table 5 and table 6 .

\subsubsection{Robust test of proposition I}

Table 5. Robust Test Results of Proposition I

\begin{tabular}{lll}
\hline Variables & Model 1 & Model 2 \\
\hline Intercept & 3.85844 & 4.33739 \\
& $(<.0001) * * *$ & $(<.0001) * * *$ \\
OA & 2.64013 & 3.04971 \\
& $(<.0001) * * *$ & $(<.0001) * * *$ \\
$\mathrm{FA}$ & 3.50042 & 2.91522 \\
& $(<.0001) * * *$ & $(<.0001) * * *$ \\
$\mathrm{X}$ & 0.29991 & 0.75639 \\
& $(<.0001) * * *$ & $(<.0001) * * *$ \\
$\mathrm{Y}$ & 1.07506 & 1.03756 \\
& $(<.0001) * * *$ & $(<.0001) * * *$ \\
\hline $\mathrm{N}$ & 6940 & 6940
\end{tabular}




\begin{tabular}{lll}
\hline F Value & $665.22 * * *$ & $690.50 * * *$ \\
\hline R-Square & 0.2769 & 0.2844
\end{tabular}

It is obvious to see from the table 5, regardless of model1 or model2, the value of the unearned revenue has $1 \%$ significant positive correlation with the enterprise value,indicating that the market position is positively affect the enterprise value, and further verify the proposition I.

4.5.2 Robust test of proposition II.

Table 6. Robust Test Results of Proposition II

\begin{tabular}{lll}
\hline Variables & Model 1 & Model 2 \\
\hline Intercept & 3.82217 & 4.29824 \\
& $(<.0001) * * *$ & $(<.0001) * * *$ \\
OA & 2.58806 & 2.99517 \\
& $(<.0001)^{* * *}$ & $(<.0001) * * *$ \\
FA & 3.45383 & 2.88239 \\
& $(<.0001) * * *$ & $(<.0001) * * *$ \\
$\mathrm{X}$ & 0.2929 & 0.74751 \\
& $(<.0001) * * *$ & $(<.0001) * * *$ \\
$\mathrm{Y}$ & 1.92901 & 1.88811 \\
& $(<.0001) * * *$ & $(<.0001) * * *$ \\
$\mathrm{Y} 2$ & -0.03586 & -0.03571 \\
& $(<.0001) * * *$ & $(<.0001) * * *$ \\
\hline $\mathrm{N}$ & 6940 & 6940 \\
\hline F Value & $541.87 * * *$ & $562.21 * * *$ \\
\hline R-Square & 0.2804 & 0.2879
\end{tabular}

From table 6 it can be seen that regardless of model 1 or model2, unearned revenue has $1 \%$ significantly positive correlation with the enterprise value while quadratic unearned revenue has $1 \%$ significantly negative correlation with the enterprise value, which indicates a inverted $\mathrm{U}$-shape existing in the influence curve of market position on the value of equity, and the proposition II is further consolidated.

4.5.3 Further Consideration of Ultimate Controller Influences

All existed papers approved that different ultimate corporate controllers lead to various marketplace position. Considering different ultimate controller influences, this paper divides companies into non-state-owned enterprises and state-owned enterprises according to the type of eventual controller.The results are shown in table 7 below.

Table 7. Results of Ultimate Controller Influences

\begin{tabular}{lllll}
\hline & \multicolumn{2}{l}{ non-state-owned enterprises } & \multicolumn{2}{l}{ state-owned enterprises } \\
\hline Intercept & 6.86048 & 6.74902 & 3.06497 & 3.03541 \\
& $(<.0001) * * *$ & $(<.0001) * * *$ & $(<.0001) * * *$ & $(<.0001) * * *$ \\
OA & 2.37372 & 2.35368 & 3.81792 & 3.71148 \\
& $(<.0001)^{* * *}$ & $(<.0001) * * *$ & $(<.0001) * * *$ & $(<.0001)^{* * *}$ \\
FA & 2.31437 & 2.33608 & 3.30048 & 3.21498 \\
& $(<.0001) * * *$ & $(<.0001) * * *$ & $(<.0001) * * *$ & $(<.0001) * * *$ \\
$\mathrm{X}$ & 0.58619 & 0.58074 & 1.3106 & 1.29172 \\
& $(<.0001) * * *$ & $(<.0001) * * *$ & $(<.0001) * * *$ & $(<.0001) * * *$ \\
$\mathrm{Y}$ & 0.54846 & 1.84581 & 1.01468 & 2.1661
\end{tabular}




\begin{tabular}{lllll}
\hline & $(0.0192) * *$ & $(<.0001) * * *$ & $(<.0001) * * *$ & $(<.0001)^{* * *}$ \\
Y2 & & -0.17213 & & -0.04318 \\
& & $(0.0011) * * *$ & & $(<.0001)^{* * *}$ \\
Observed value & 2676 & 2676 & 4264 & 4264 \\
F & $230.85 * * *$ & $187.49 * * *$ & $524.13 * * *$ & $431.08 * * *$ \\
Adjusted & 0.2558 & 0.2585 & 0.3296 & 0.3357 \\
R2 & & & & \\
\hline
\end{tabular}

It can be seen from table 7, whether it is non state-owned enterprises or state-owned enterprises, unearned revenue is statistically significant positive correlation with the value of the enterprise while quadratic unearned revenue has $1 \%$ significantly negative correlation. The results shows that market position is positively related to enterprise value,but there will be extreme value. It is a kind of inverted U-curve,which further verifies the proposition I and the proposition II and also shows that the impact of the ultimate controller is not significant.

\section{Conclusions And Shortcomings}

\section{1 conclusions}

This paper focuses on listed companies in the manufacturing industry in China, and finds the relationship between market position and company's equity value. A higher marketplace position means a larger influential power in the market and the corporation's equity value would be improved due to increasingly strengthened attention and recognition by the market. However, the relationship between the two factors is not completely linear relation but a inverted U-shape with an extreme value. It might be a reality. An overwhelming height of market position would bring the company into an extreme of monopoly which is a lure for the government to classify this business as the "anti-monopoly" object, and eventually diminish its positive effects on enterprise value of equity.

\subsection{Shortcomings}

The shortcomings of this paper, on the one hand, the empirical test only focuses on the manufacturing industry, not expanding to other industries.On the other hand, this paper is to study the relationship between the market position and the value of equity in the static state,and in fact, the enterprise is changing and developing.Should we study the relationship between the two in a dynamic way? This will also become the author's research direction and focus in the future.

\section{References}

Ohlson, J. A. (1990).Synthesis of Security Valuation Theory and the Role of Dividends, Cash Flows and Earnings[J]. Contemporary Accounting Research. 1990(V7), 648-676

Ohlson, J. A. (1995). Earnings, Book Values and Dividends in Equity Valuation[J]. Contemporary Accounting Research. 1995(11), 661-687

Feltham, G., \& Ohlson, J. (1995). Valuation and Clean Surplus Accounting for Operating and Financial Activities[J]. Contemporary Accounting Research, 1995(11), 689-731

Feltham, G., \& Ohlson, J.(1996). Uncertainty Resolution and The Theory of Depreciation Measurement[J]. Journal of Accounting Research, 1996(34), 209-234

Myers, J. N. Implementing Residual Income Valuation with Linear Information Dynamics[J], The Accounting Revies, 74(1), 1-28

Wang, L. X., \& Gan, L. N. (2016).Theoretical and Empirical Analysis of Market-power adjusted RIM Model[J], International Journal of Economics and Finance, 8(2), 147-155, 2016.

\section{(cc) $\mathrm{BY}$}

This work is licensed under a Creative Commons Attribution 3.0 License. 